\title{
The role of the doctor in the Mental Health Review Tribunal*
}

\author{
P. Grahame Woolf $\dagger$, 2a Vanbrugh Hill, Blackheath, London SE3 7UF
}

This paper draws upon over 30 years experience of Tribunals as RMO, medical member and independent psychiatrist.

The Mental Health Review Tribunal was established under the Mental Health Act (1959). The 1983 Mental Health Act and the Tribunal Rules (Statutory Instruments, No. 942) have strengthened its scope and go further towards protecting the civil liberty of the psychiatric patient. There are people, including psychiatrists, who believe that UK legislation has now gone too far, but Jill Peay (1990) argued persuasively that a cautious approach by tribunals still failed to adequately safeguard the liberty of some detained patients.

Tribunals are demanding and costly in terms of disbursements to participants and the hidden costs of the professional time of hospital and social work staff. Resentment surfaces occasionally, with resistance to statutory requirements, reports lacking or inadequate, and key witnesses unavailable.

Tension and conflict are intrinsic to the situation but, with understanding on all sides, can be minimised with a positive resolution and benefit to family members and professionals from a rare opportunity to all meet together. A patient's representative in his final submission said recently that the hearing had been "a helpful dialogue and a creative time". Compliments, however, are infrequent and some psychiatrists feel themselves unwarrantably bruised by tribunal experiences!

The role of the doctor will be considered in three categories. (Doctors and patients are referred to as male throughout.)

(a) The health authority's medical evidence is provided by the consultant psychiatrist (designated Responsible Medical Officer) or a junior doctor from his clinical team.

(b) This evidence will be probed at the hearing by the medical member of the MHT, who has to see the patient beforehand and expects to study the case-file.

*Abridged from a lecture given to Royal College of Psychiatrists Southern Division Autumn Meeting at Sir Christopher Wren's House, Windsor on 9 November 1990.

† Medical Member of Mental Health Review Tribunal since 1966; formerly Consultant Psychiatrist, Central Hospital, Warwick and Darenth Park Hospital, Dartford, Kent. (c) The patient's legal representative may be assisted by an independent psychiatrist who examines the patient, prepares a report and may be invited to give evidence at the hearing.

\section{Responsible Medical Officer}

Careful preparation of health authority reports is a pre-requisite for constructive hearings. To obviate fundamental misunderstandings, the doctor preparing the medical report must study carefully the relevant section of the Mental Health Act under which his patient is detained. Familiarity with the Tribunal Rules (especially Schedule 1, Part B (1) re. preparation of reports) is necessary and the Memorandum on Parts I to VI etc (1987) offers additional assistance.

Trouble may stem from the initial detention process. In many hearings the eventual decision turns upon a submission that the Section under which a patient is held is inappropriate. Doctors recommending detention should guard against the "least restrictive" criterion sometimes advocated, resulting in many patients known to the hospital team being placed under S2, when non-compliance is the central issue. Frequently, S3 is satisfactory and very appropriate, allowing for extended leave and greater flexibility, with recall to hospital as a last resort if community supervision fails (Code of Practice, 1990).

S2 patients, however, ought to be detained in hospital and are entitled to review by a tribunal within one week of application. This requirement precludes negotiation with the hospital for convenient timing. Other disadvantages arise if S2 patients and their case-notes are not on the ward or readily available for necessary interviews.

All reports should be prepared and despatched swiftly. Good reports are the basis for good hearings. They should address the central issues relating to the need for detention and provide sufficient background to assist participants who will not have access to the hospital case-notes. If reference is made to earlier reports, these must be appended to the papers distributed to all parties.

Reports for S2 hearings may not be available for postal delivery, but a copy placed in the ward case file 
will be of considerable value to medical members and independent psychiatrists conducting preliminary examinations.

Dr G. Langley (1990) takes it as axiomatic that the doctor preparing reports and appearing before tribunals is the Responsible Medical Officer, the consultant psychiatrist. While this is not always possible, it is unreasonable for inexperienced and unprepared junior doctors to be thrown in at the deep end. Expensive adjournments often occur because a doctor detailed to attend does not know the patient, and may not even have had an opportunity to discuss the case fully with the responsible consultant. It is sometimes helpful if consultant and ward doctor both attend and are prepared to supplement each other's evidence upon request. Tribunals will often hear the medical evidence first and normally take doctors' work pressures into account.

RMOs have occasionally intimated an intention neither to attend nor to send a delegate, because of work priority considerations. In the interests of good relations, and speedy determination of an application, the Tribunal is always reluctant to adjourn to subpoena an essential witness. The contribution of the hospital doctor is of paramount importance. In his absence, satisfactory hearings are virtually impossible. This legal requirement should be addressed during the current national review of Consultants' Job Plans and Contracts.

Doctors of whatever seniority who represent the health authority should steel themselves to accept, with as good grace as they can muster, that questioning may be searching. Some solicitors feel bound to seek to "win" according to their clients' instructions, rather than being satisfied to assist the tribunal to make a determination according to the patient's best interests. Counsel engaged to represent patients can find themselves in an anomalous situation, because barristers have a duty to supply advice, which may conflict with instructions. Tribunal proceedings are intended to be inquisitorial, not adversarial, and decisions are subject to judicial review. If questions appear to be going beyond reasonable bounds, the President may assist in limiting fruitless lines of questioning, which should never amount to hostile cross-examination.

A verbal update based upon recent re-examination will often be appropriate. Medical evidence is normally tested in the presence of the patient, a practice which caused apprehension when it was first introduced. However, fears for impairment of the doctor/patient relationship have proved generally unfounded. Some doctors take umbrage when they feel that their clinical judgement is being challenged on legalistic grounds. They should appreciate that the legal issues confronting the tribunal, which are always in the forefront of the representative's mind, are often very different from the clinical consider- ations which are paramount for the doctors. Although Rule 22 provides that the proceedings should "seek to avoid formality", a hearing should not be allowed to drift into a "case conference".

If changes make continued detention unnecessary, the order should be discharged forthwith by the RMO (who has a duty to keep the need for compulsory detention under continual review) and the Tribunal office promptly informed. A common reason for a tribunal's decision to discharge an order is that, on the day, the doctor representing the health authority makes no attempt to present any cogent argument to justify continued detention.

Most medical members will know of patients they had thought to still need detention upon preliminary examination, but who were discharged by the RMO very soon afterwards, shortly before the hearing. In these circumstances, up-to-date reports are generally not prepared, so the basis for such discharges remains unexplained and provokes speculation. Very late discharges are rarely necessary or justifiable clinically, but are common and cause ill-feeling. Participants may not receive cancellation notice and resent travelling considerable distances for a non-event.

\section{Medical member}

The medical member of the panel has a complex role (Finestein, 1988). At his preliminary examination of the patient and study of the case file, if possible at least several days before the hearing, he will check that the patient understands the procedure. He will also assess his ability to represent himself, advising him when legal representation appears necessary or advantageous, and alerting the ward staff to assist with the arrangements. Too many tribunals have to be adjourned because a patient's legal representation is not achieved in good time before the hearing.

During the half-hour prior to the hearing, the medical member will often be invited to outline the case, although some Presidents prefer not to hear from him until after the evidence, but he should never pre-empt the decision. He will take part in the discussion of procedure, and may suggest an appropriate order in which witnesses might be heard. He alerts the President and lay member to the patient's level of comprehension and insight, brings out material factors which do not appear in the reports and ensures that these emerge openly during the hearing.

It will be for him to seek to clarify medical evidence as to diagnosis, treatment and future plans, assisting those doctors who may be unfamiliar with the complicated legal jargon of the Act and Rules. If the patient is unrepresented, the medical member may question the RMO more forcefully than would otherwise be necessary, to ensure that the patient's case is not jeopardised by lack of medical and legal 
knowledge. Hospital doctors should endeavour to take this in good part, not as an attack upon their clinical judgement.

After the hearing the medical member normally takes a vigorous part in the panel discussion, but hospital staff should understand that it is not uncommon for the medical view to have been overruled in a majority decision.

\section{Independent psychiatrist}

The legal representative may seek legal aid to obtain an independent report, supported when necessary by oral evidence. Patients with means, not entitled to legal aid, are placed in an invidious position and resent being expected to pay for their efforts to escape compulsory detention when they have "done nothing wrong".

Section 76 of the Act provides for the independent psychiatrist to have free access to see the patient and study all notes and records. He will endeavour to satisfy himself that the RMO's report represents the patient's condition fairly. His own report should endeavour to be neutral; it is then for the representative and the patient to decide how the report is used. Often reports are not disclosed when they do not advance the applicant's case for discharge. They are, however, considered reviews, usually paid for out of public funds, prepared by psychiatrists who devote a considerable amount of time to the patient's case, so it is unfortunate that they should be 'buried' for tactical reasons when they may well contain points which might help in the patient's management.

Lengthy, over-inclusive medical reports, whether from RMOs or independent psychiatrists, may be counter-productive. As with all medico-legal reports, it is important to focus upon the key issues at the centre of the determination. It is in everyone's interests that hearings should not be unduly prolonged with what turn out to be irrelevancies.

\section{Admissions and medication}

The Tribunal cannot become embroiled in complaints about the manner of the initial detention nor can it become deeply involved in details of medication, which must remain at the discretion of the RMO, with the role of the MHAC in the background for consultation when appropriate. Confusion between the roles of Managers, Commission and Tribunal remain rife, even though the 1983 Act has been in operation for some six years.

\section{Dangerousness}

The foregoing deals mainly with detention under Part II and with Part III patients not subject to restriction orders. In cases of applications and automatic references concerning restricted patients (S37/41) convicted of serious offences, the cautious approach of the Home Office and Judge/QC Presidents of Restricted Tribunal Panels is understandable. Patients at special hospitals are disadvantaged because the strict regimes rarely provide any opportunity to test their behaviour in freer surroundings. Patients, RMOs and independent psychiatrists are sometimes all in agreement that speedier rehabilitation is appropriate, but an impasse in negotiations with the Home Office may have been reached because of lack of acceptable vacancies in conditions of lesser security.

In preparation for these hearings in which dangerousness will be a central issue, it is particularly important that the fullest possible reports should be offered, addressing questions of insight into the circumstances of the index offence and future risks to the public. These are some of the cases in which independent psychiatrists, psychologists and social workers may have significant roles, and in which their oral evidence may assist the tribunal to make a just determination. The contributions of all participants would benefit from study of Risk-taking in Mental Disorders (Carson, 1990).

\section{References}

Carson, D. (ed.) (1990) Risk-taking in Mental Disorders: Analyses, Policies and Practical Strategies. Chichester: SLE Publications.

Finestein, His Honour Judge I. (1988) The medical member. MHRT Members' News Sheet, 2.

Langley, G. E. (1990) The Responsible Medical Officer and Mental Health Review Tribunals. Psychiatric Bulletin, 14, 336-337.

Peay, J. (1990) Mental health review tribunals. Principles and Practice of Forensic Psychiatry. Chapter XIV.3. London: Churchill Livingstone.

S2 or S3 (1990) Code of Practice, 5. HMSO. 